\title{
Modeling of Returns of Nairobi Securities Exchange 20 Share Index Using Log-Normal Distribution
}

\author{
Joab Odhiambo $^{1 *} \quad$ Patrick Weke $^{1} \quad$ Jusper Wendo $^{2}$ \\ 1.School of Mathematics, University of Nairobi, PO BOX 30197-00100, Nairobi, Kenya \\ 2.Faculty of Science, Catholic University of Science of East Africa, P O Box 62157 - 00200, Nairobi, Kenya
}

\begin{abstract}
Nairobi Securities Exchange 20 Index Share (NSE-20 Share Index/ An Exchange Traded Fund) has been one of the investment avenues for both Kenyans and foreign investors look whenever they want to make sound investments decisions in the market. However, the assumption that the daily securities index prices follows a normal distribution has been disputed by data in several cases. This means new statistical distributions must be used to discern the distribution of NSE-20 Share Index thus enabling investors make prudent financial decisions to avoid financial loses. In this research paper, we will model the prices of daily securities index using a log-normal distribution. This is because the distribution follows a positive trend before we can ascertain on how well it fits the already available data at the NSE market. This research paper recommends that a log-normal distribution best fits data of the daily prices of NSE-20 Share Index for those investors who would like to model the future of the market before making financial decisions.
\end{abstract}

Keywords: Daily Returns, Volatility, Healthy-Tailed Distribution, NSE-20 Share Index, Log-normal Distribution DOI: $10.7176 / \mathrm{RJFA} / 11-8-08$

Publication date: April $30^{\text {th }} 2020$

\section{Introduction}

A securities market index such as NSE-20 Share Index is a measure sensitively of the respective cumulative securities prices of the index to the market performance. It also gives an overview of how the market performance for the investors who would like to make investment at any of the traded securities. The securities indexes are often tabulated daily by summarizing the daily movement of the list of 20 securities that makes the index for investors to get information on the general performance of the market as by [3] . In addition, you can use all the securities prices movements such as NSE All Securities Index commonly known as NASI.

NSE All Share Index (NASI) is also an important index that shows the overall performance of the market for the investors interested in all sectors of the Kenyan economy as opposed to NSE-20 share Index. This is because it incorporates all the number of traded securities in a daily basis as []․ It is important again because it given the overall capitalization of the market as time moves thus helping in making a comparison with the NSE-20 share index from [9] analysis.

The NSE-20 Securities index often measures the expected value of performance of top 20 large capitalization securities drawn from different sectors of industries in the Kenyan market traded at the securities exchange market as in [2]. While in most cases, securities prices are often assumed to follow a normal distribution, this might not be cases when modeling the prices movements.

Many trading theories have been developed when modeling the randomness of securities index using the concept of random walks movement of security prices such as central-limit theorem on the daily prices that do not represent the reality of trading at the trading stock markets. This means both weekly as well as monthly price changes might not have a normal or a Gaussian distribution when trading in the market. However, the incidence of extreme events such as the breakdown of a pandemic in the global market such as Covid-19 might have huge impact on the performance of the stock index thus helping an investor make a sound financial decision while trading in the market as per[4]. The price changes in most cases are leptokurtic meaning that it has too many price values near the expected return of the day as well as many out within the extreme tails of the distribution in case of a heavy-tailed distribution.

While many heavy-tailed distributions such as student-t distribution as been used to model the volatility of the securities exchange market as by [10], the concept of "fatness of the tail" differs in cases of extreme value of events such as currently experienced market returns after the Covid-19 events. During the study of the author, the daily cumulative distribution of return of the stock index fitted well the Taiwan stock index such brought out the issue of heavy-tailed distribution.

While logistic distribution has been an option of general stochastic model measurement as illustrated by [11], it is commonly used in risk measurement within financial assets returns. It was noted in the paper that portfolio diversification is one way of reducing the high levels of volatility that exists in the market especially during extreme times of trading as per [6]. The future growth of stock market prices often follows a generalized linear model that predicts the future market.

In this paper, we intend to model the daily prices of NSE-20 share Index using a log normal distribution to 
take into considerations the heavy tailed that is likely to experience in the market after crushes due to pandemic like Covid-19 virus experienced in the market today in Kenya. The data available in the securities exchange market should be able to fit the data well to offer information for future traders when making trading decisions to avoid loses likely to be experienced in the future.

\section{NSE-20 Share Index Modeling}

\subsection{Mathematical Preliminaries of Log-normal Distribution}

A lognormal) distribution commonly known as log-normal distribution is a continuous PDF of a random variable where natural logarithms of the individual random variables are normally distributed as [] $]$. This means that when you take the natural logarithms of the random variables, the random variables will normally be distributed with mean $=\theta$ and variance $=\sigma^{2}$. Therefore, if a random variable $X$ with log-normally distributed, then $Y=\ln (X)$ follows a normal distribution. On the contrary side, if $\mathrm{Y}$ has a normal or Gaussian distribution, then $\mathrm{Z}$ distribution of the exponential function, $X=\exp (Z)$, has a log-normal distribution. The feature of a log normal distribution that makes it necessary when modeling the NSE-20 Share Index only takes positive values while taking care of the possibility of extreme events during trading in the financial markets.

Let $\mathrm{Z}$ to be defined as a standard normal distribution with mean $=0$ and variance $=1$. This means that distribution of a random variable.

$$
Y=e^{\theta+\sigma Z}
$$

where $Y$ has a $\log$-normal distribution with parameters, mean $=\theta$ and variance $=\sigma^{2}$. Let the probability density function be given by $f(y)$, then then;

$$
\begin{gathered}
f(y)=\frac{d}{d y}\left(P[Y \leq y]=\frac{d}{d y} P[\ln Y=\ln y]=\frac{d}{d y}\left[\Phi\left(\frac{\ln y-\theta}{\sigma}\right]\right.\right. \\
f(y)=\zeta\left(\frac{\ln y-\theta}{\sigma}\right) * \frac{d}{d y}\left(\frac{\ln y-\theta}{\sigma}\right) \\
f(y)=\zeta\left(\frac{\ln y-\theta}{\sigma}\right) * \frac{1}{d y} \\
f(y)=\zeta\left(\frac{\ln y-\theta}{\sigma}\right) * \frac{1}{d y} \\
f(y)=\frac{1}{y} * \frac{1}{\sigma \sqrt{2 \pi}} \exp \left\{\left(\frac{\ln y-\theta}{\sigma}\right)\right\}
\end{gathered}
$$

In terms of the cumulative density function, $C D F$, the log-normal distribution will be;

$$
\begin{gathered}
F(Y)=\int_{\text {ally }} f(y) d y \\
F(Y)=\Phi\left(\frac{\ln y-\theta}{\sigma}\right)
\end{gathered}
$$

From equation (0.0.3), the mean and variance of the log-normal distribution will be given by;

$$
\begin{gathered}
\text { mean }=[E(y)]=e^{\left(\theta+\frac{\sigma^{2}}{2}\right)} \\
\text { variance }=[E(y)]^{2}\left(e^{\sigma^{2}}-1\right)
\end{gathered}
$$

\subsection{Return Modeling}

The series of NSE-20 share Index returns can be defined as;

$$
\begin{gathered}
R_{t}=\frac{\ln S_{t+1}}{\ln S_{t}} \\
R_{t}=\log S_{t+1}-\ln S_{t}
\end{gathered}
$$

where $\mathrm{Rt}$ is the return on an NSE-20 share Index at time $\mathrm{t}$ and the NSE-20 share Index at time $\mathrm{t}+1$ for $\mathrm{S} \mathrm{t}+1$ and $\mathrm{t}$ 
for $\mathrm{S} t$ respectively during the time of trade. It is important to note that the Return on NSE-20 share Index is modeled as log-normal distribution with the mean and variance of returns given above.

\section{Modeling Fitting and Data Analysis \\ 3.1 Fitting the NSE-20 Share Index Data}

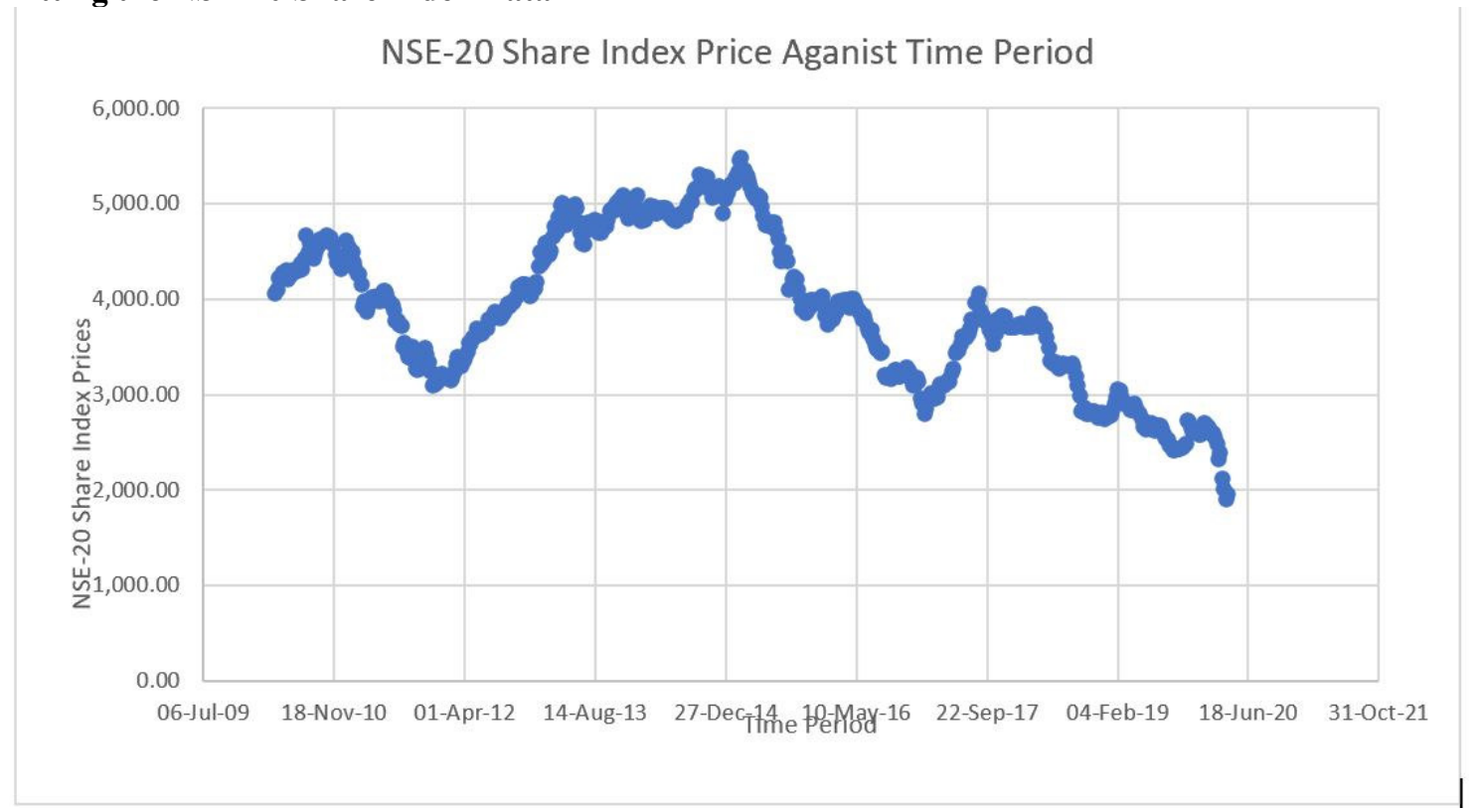

Figure 1: NSE-20 Share Index Trading Against Time

It is important to summarizes the relevant information on the empirical log-normal distributions of securities index returns under different consideration. The vital statistics that needs to reported includes mean, variance, standard deviation, minimum as well as maximum level of return during the trading period, kurtosis and coefficients of skewness.

\begin{tabular}{|l|l|}
\hline Mean & 3888.886 \\
\hline Variance & 655354.3 \\
\hline Standard Deviation & 809.5395 \\
\hline Maximum Return & 5491.37 \\
\hline Minimum Return & 1917.67 \\
\hline Skewness & -0.03806132 \\
\hline Kurtosis & 2.038016 \\
\hline
\end{tabular}

Table 1: Sample Moments Distributions of the NSE 20 Share Index

From statistics analysis from [12], the third central moment is referred as an asymmetry measure or skewness within the specified distribution. From results illustrated in table 1, it is important to note the data distribution is not symmetrical as it is negatively skewed with the skewness coefficient of -0.03806132 . In addition, the kurtosis, which is a measure of general peakedness or just flatness near the center of the distribution degree. The ratio is obtained by getting the ratio of the 4th central moment before dividing it by the variance square. For a normal distribution, the ratio should be equal to 3. Any ratio that is greater than 3 does indicate that more values within the neighborhood of its mean (which is more peaked compared to the normal or Gaussian distribution). From the analysis of our NSE-20 share index data, it is a heavy tailed, which is an excess kurtosis. This is shown by the coefficient of kurtosis of 2.038016 . We can conclude that our data is mesokurtic

\subsection{Non-normality Assumption Test}

For purposes of testing for normality, we will assume that NSE- 20 share index Prices follows a normal distribution with mean $=\theta$ and variance $=\sigma^{2}$. The pdf will be given by;

$$
f(y)=\frac{1}{\sigma \sqrt{2 \pi}} \exp \left\{-\frac{1}{2}\left(\frac{\ln y-\theta}{\sigma}\right)^{2}\right\}
$$


The distribution of NSE-20 share Index from the Nairobi Securities Exchange market, are assumed not to follow a normal distribution to take into consideration the presence of extreme events such the existing presence of Covid-19 that massively affects the behavioral of investors. Using the procedure of [1], which as assumption that all data available at NSE is not normal. We will obtain the MLEs of the normal distribution as well as their corresponding standard errors. The results are shown below;

\begin{tabular}{|l|l|l|}
\hline Parameters & Estimates & Standard Error \\
\hline$\theta$ & 3888.886 & 0.0189152 \\
\hline$\sigma$ & 809.5395 & 0.0134072 \\
\hline
\end{tabular}

Table 2: Maximum Likelihoods Estimates of the Normal Distribution

From the above table 2 , the estimation of the parameters are as follows; $\theta=3888.886$ and $\sigma=809.5395$ with the standard error of 0.0189152 and 0.0134072 respectively. While these are parameters for the normal distribution, we can use the same parameters to obtain the parameters of the log-normal distribution as in equation (0.5) and (0.6) respectively.

$$
\begin{gathered}
e^{\left(\theta+\frac{\sigma^{2}}{2}\right)}=3888.886 \\
{[E(y)]^{2}\left(e^{\sigma^{2}}-1\right)=655354.3}
\end{gathered}
$$

Solving equation 0.0 .9 and 0.0 .10 simultaneously;

$$
\begin{gathered}
\left(e^{\sigma^{2}}-1\right)=\frac{655354.3}{3888.886^{2}}=0.0433342 \\
e^{\sigma^{2}}=1.0433342 \Longrightarrow \sigma^{2}=\ln 1.0433342 \\
\sigma=\sqrt{0.04242} \Longrightarrow \sigma=0.206
\end{gathered}
$$

Replacing back the value of $\sigma$ to equation 0.0 .9 to obtain the value of $\theta$,

$$
\theta=\ln (3888.886)-\frac{0.206}{2}
$$

$$
\theta=8.256
$$

From equation (0.11) and (0.12), we can derive that the value of NSE-20 share Index follows a log-normal distribution with parameters, $\theta=8.256$ and $\sigma=0.206)$ i.e. $\mathrm{Y} \sim \operatorname{LG}(\theta=8.256, \sigma=0.206)$.

On testing of the correlation between the different prices of the NSE-20 share Index during day trading, the results are in the figure below: 


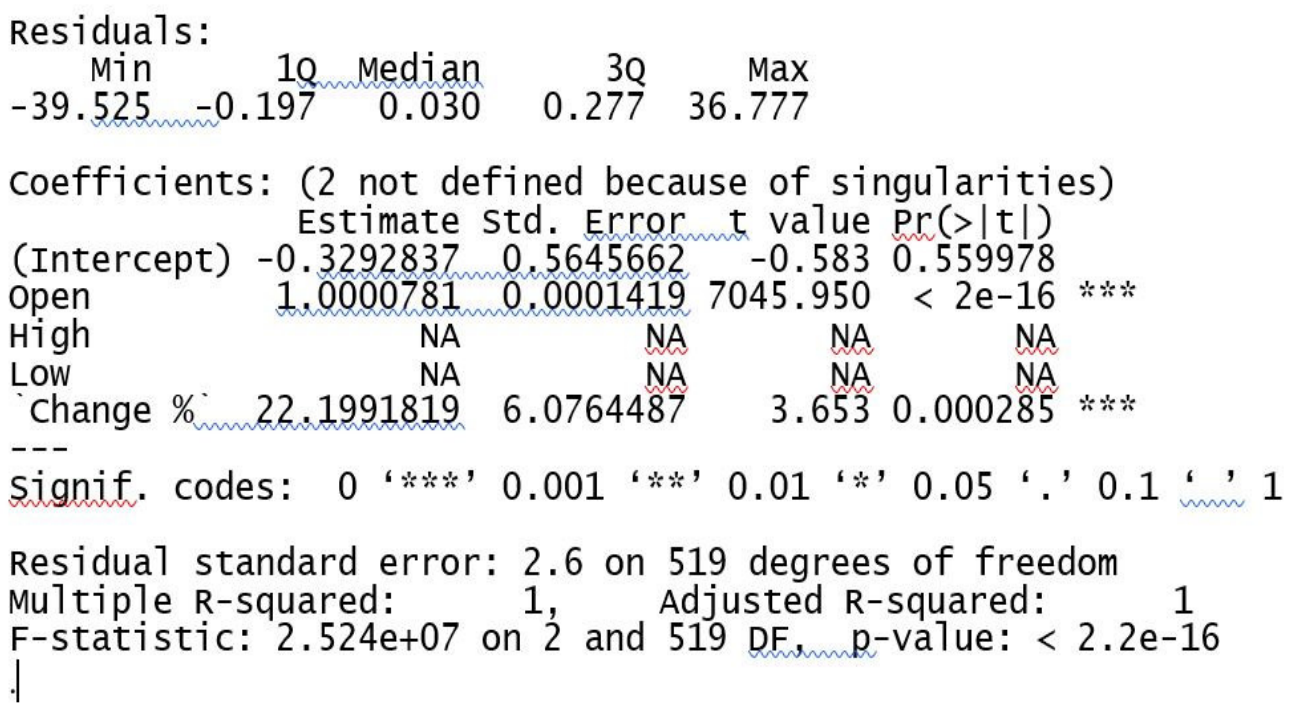

Figure 2: Relationship between Daily Lows and Highs of NSE-20 Share Index

\subsection{Fitting a Log-Normal Distribution}

With the data available at the NSE website, we can be able to fit the data with the log-normal distribution after estimation of the parameters to obtain new fitted data. The data is then used to model the new prices of NSE-20 share index that follows a long normal distribution with the estimated levels of volatility of the market compared to findings of $[\underline{13}]$ paper.

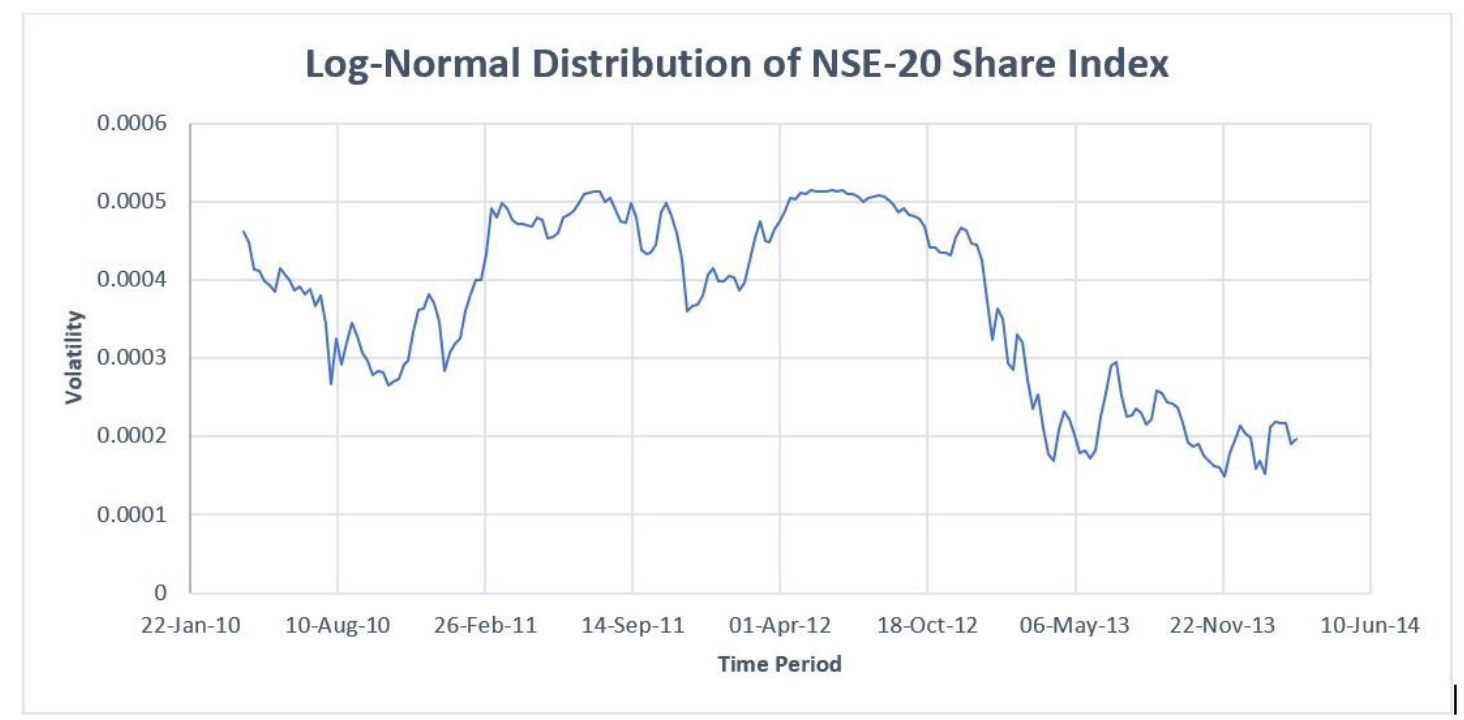

Figure 3: Estimated volatility of the NSE-20 share Index

From figure 0.3 , we can see that the daily volatility of the NSE-20 share Index is stochastic during the duration of trading in the market. The values change daily as the value of the securities index changes during the trading periods with the mean volatility obtained in equation $(0.11)$.

\section{Conclusion and Recommendations}

The aim of this study was to fit an empirical probability distribution to the Kenyan NSE 20 share index. The research paper used a log-normal distribution, we were finding returns in terms of logarithms price index as opposed to the simple price index changes. The argument is that the natural logarithms of price is the return, that has a continuous compounding, which you earn when hold the specific security for a particular day.

The research paper has shown from figure 0.2 that variability of security price index changes that makes it an increasing price index function. However, by taking the natural logarithms can neutralize the effects on price index levels. From the descriptive analysis, the historical data of NSE-20 share price index data shows that it heavy tailed and non-symmetrical as assumed by most papers. With skewness coefficient of and low kurtosis, the data is mesokurtic which disputes the previous assumptions. With the assumption that volatility of the NSE-20 Share 
Index is constant over the period of trading is flawed since it changes over time as in figure 0.3 when making investments.

From our results, we can affirm that log-normal distribution fits the NSE-20 share Index data when modeling the market trends especially when taking into considerations the cases of extreme events during the period of study. Since the trends of NSE-20 share Index are heavy tailed, it offers a clear evidence that the changes in price over a unit of time interval is not a constant variable. We can conclude that the future predictions of the NSE 20 Share Index returns should be based on a log normal distribution as opposed to a normal distribution. In addition, we recommend an investigation of the inverse gamma normal mixture distribution if it can best fit the returns of NSE 20 Share Index return as well as other normal mixtures. This research should investigate on how well the specified distributions can fit the same NSE-20 share Index data.

\section{References}

[1] Aloys Ayako, Georger Kungu, and Thomas Githui. Determinants of the performance of firms listed at the nairobi securities exchange. Research Journal of Finance and Accounting, 6(12):157-164, 2015.

[2] J Bosire. The effect of automation on stock market price volatility: A case ofnairobi securities exchange. IOSR Journal of Economics and Finance, 5(3):71- 79, 2014.

[3] Rasitha R Jayasekare, Ryan Gill, and Kiseop Lee. Modeling discrete stock pricechanges using a mixture of poisson distributions. Journal of the Korean Statistical Society, 45(3):409-421, 2016.

[4] Hung-Chun Liu and Jui-Cheng Hung. Forecasting s\&p-100 stock index volatility: The role of volatility asymmetry and distributional assumption in garch models. Expert Systems with Applications, 37(7):4928-4934, 2010.

[5] Arfa Maqsood, Suboohi Safdar, Rafia Shafi, and Ntato Jeremiah Lelit. Modeling stock market volatility using garch models: A case study of nairobi securities exchange (nse). Open Journal of Statistics, 7(2):369-381, 2017.

[6] Arfa Maqsood, Suboohi Safdar, Rafia Shafi, and Ntato Jeremiah Lelit. Modelingstock market volatility using garch models: A case study of nairobi securitiesexchange (nse). Open Journal of Statistics, 7(2):369-381, 2017.

[7] Jalira Namugaya, Anthony GWaititu, and Abdou Kâ Diongue. Forecasting stock returns volatility on uganda securities exchange using tsk fuzzy-garch and garch models. 2019.

[8] Bright O Osu. A stochastic model of the variation of the capital market price. International Journal of Trade, Economics and Finance, 1(3):297, 2010.

[9] Patrick K Owido, SO Onyuma, and G Owuor. A garch approach to measuring efficiency: a case study of nairobi securities exchange. Research Journal of Finance and Accounting, 4(4):1-16, 2013.

[10] Clemens Reimann, Peter Filzmoser, Robert Garrett, and Rudolf Dutter. Statistical data analysis explained: applied environmental statistics with R. John Wiley \& Sons, 2011.

[11] Henry C Thode. Testing for normality, volume 164. CRC press, 2002.

[12] Kai-Yin Woo, Chulin Mai, Michael McAleer, and Wing-Keung Wong. Review on efficiency and anomalies in stock markets. Economies, 8(1):20, 2020. 